Title: Scalable methodology for large scale building energy improvement: relevance of calibration in model-based retrofit analysis

Authors: Yeonsook Heo ${ }^{\mathrm{a}}$, Godfried Augenbroe ${ }^{\mathrm{b}}$, Diane Graziano ${ }^{\mathrm{c}}$, Ralph T. Muehleisen ${ }^{\mathrm{c}}$, and Leah Guzowskic

${ }^{a}$ Department of Architecture, University of Cambridge, Cambridge, UK

${ }^{\mathrm{b}}$ College of Architecture, Georgia Institute of Technology, Atlanta, GA, USA

${ }^{\mathrm{c}}$ Decision and Information Sciences Division, Argonne National Laboratory, Lemont, IL, USA

\begin{abstract}
The increasing interest in retrofitting of existing buildings is motivated by the need to make a major contribution to enhancing building energy efficiency and reducing energy consumption and $\mathrm{CO}_{2}$ emission by the built environment. This paper examines the relevance of calibration in model-based analysis to support decision making for energy and carbon efficiency retrofits of individual buildings and portfolios of buildings. The authors formulate a set of real retrofit decision-making situations and evaluate the role of calibration by using a case study that compares predictions and decisions from an uncalibrated model with those of a calibrated model. The case study illustrates both the mechanics and outcomes of a practical alternative to the expert- and time-intense application of dynamic energy simulation models for large-scale retrofit decision-making under uncertainty.
\end{abstract}

Keywords: large-scale retrofit analysis, Bayesian calibration, normative model, uncertainty analysis

Corresponding author. Email: yh305@cam.ac.uk

Tel.: (+44)1223760114 


\section{Scalable methodology for large scale building energy improvement: relevance of calibration in model-based retrofit analysis}

\section{Introduction}

Retrofitting existing buildings to achieve higher energy efficiency is one of the best ways to reduce energy consumption and $\mathrm{CO}_{2}$ emissions. Approximately $40 \%$ of the US and UK's energy consumption is attributed to the building sector [1,2]. This energy is predominantly consumed by existing buildings that account for $98 \%$ of the total floor area in comparison to new buildings constructed every year [3]. The International Panel on Climate Change (IPCC) reported that cost-effective energy efficiency measures in the existing building stock can save 5.3-6.7 $\mathrm{GtCO}_{2}$-eq per year in 2030 [4]. According to the Carbon Trust report, implementation of retrofit technologies in existing non-domestic buildings can lead to $15 \%$ reduction in $\mathrm{CO}_{2}$ emission in UK [5]. Based on a statewide study of energy efficiency potentials in existing commercial buildings, Xenergy and Northwest Power Planning Council reported that energy retrofits can achieve 18\% energy savings in California [6] and 12\% in Washington, Oregon, and Idaho, respectively [7]. These studies point to energy retrofits of existing buildings as essential to achieving reduction targets in energy consumption and $\mathrm{CO}_{2}$ emissions from the commercial building sector.

In response to this need, US Federal, state, and city governments have established retrofit initiatives and programs to promote the reduction of energy consumption by the building sector. President Obama launched the "Better Buildings Initiative" with a target of reducing energy consumption by $20 \%$ in commercial buildings by 2020 through cost-effective retrofit interventions [8]. Under this initiative, more than 190 organizations have committed to improving the energy efficiency of 3 billion square feet of floor area. At the city scale, the city of Chicago initiated the Chicago Climate Action Plan with targets to achieve $30 \%$ energy reduction by 2020 through retrofitting $50 \%$ of existing commercial and residential buildings in the city [9].

Reaching these energy efficiency goals will rely on the decisions made by public agencies in planning policy and incentives, utilities in executing energy efficiency programs, financiers in providing capital to the market, energy service companies (ESCOs) in developing profitable business models, and building owners in investing in energy efficiency retrofits. These stakeholders face decisions that span individual buildings, portfolios of buildings, and large aggregates of buildings. Their decisions will be based on evaluations of benefits and risks associated with decision options that aim to facilitate implementing optimal energy efficiency technologies. Currently, there are gaps in the analytic tools available to support these decisions at different scales.

To support retrofit decisions, analysis has been performed on the basis of different methods for modelling building energy performance. For supporting policy and planning design, prototypical (or archetypical) models that represent a certain group of buildings are commonly used to evaluate the effect of energy efficiency measures on reducing energy consumption at city scale. Examples of recent work on the subject include the framework of categorizing the housing stock into a set of clusters [10,11,12], buildingcluster energy consumption models for the US commercial stock [13], and district clustering approach modelling using prototypical building models for predicting end-use energy consumption at city level [14]. Since targets for retrofit policy are individual buildings, the policy perspective needs to be translated 
into specific retrofit plans which can be implemented building by building. In this stage, energy retrofit projects follow the International Performance Measurement and Verification Protocol (IPMVP) for determining energy savings from retrofit interventions $[15,16]$. This determination typically involves a detailed audit process for modelling each building in detail, calibrating the model, and reliably predicting the effects of retrofit options [17,18,19]. A high cost associated with the detailed audit prohibits costeffectively implementing the most optimal mix of energy efficiency measures (EEMs) for each building within the target region. It can be reasonably applied only for one or several buildings, but does not scale up to large sets of buildings. Hence, implementing energy efficiency improvements in a large set of buildings will need a new generation of scalable and adaptable modelling methodologies to correctly evaluate feasible retrofit options for every building in the portfolio.

Quantifying risks associated with EEMs is important to investment decisions and incentive programs. Energy efficiency programs and financial schemes require measurement and verification $(\mathrm{M} \& \mathrm{~V})$ of energy savings achieved in a building as one of the major requirements to provide subsidies to building owners who invest in energy retrofits. Moreover, quantifying underperformance risks associated with EEMs is essential in the ESCO business model. ESCOs undertake energy retrofits through performance based contracts that guarantee certain savings and compensate the customer for savings not realized. So, they need to factor in the underperformance risk into their pricing structures. Despite the importance of risk analysis, current standards (e.g., IMPVP and ASHRAE guideline 14) follow a deterministic approach that ignores uncertainty in the retrofit decision-making process.

This paper presents a retrofit decision-making environment that accommodates decision support needs at different scales with explicit risk management. The environment is based on a scalable, probabilistic methodology that has three major features: (1) normative energy models, (2) Bayesian calibration, and (3) uncertainty analysis. The key element of the methodology is the application of normative energy models that enable modelling a large portfolio of buildings. We demonstrated through case studies that normative models supported by Bayesian calibration correctly evaluate EEMs in comparison to similarly calibrated detailed simulation models and support risk-conscious decision-making [20,21]. Nevertheless, deploying the methodology into different decision-making contexts leads to the question of how to adequately analyse retrofit options in different contexts. Particularly, this paper questions whether model calibration is necessary for all decision-making situations by evaluating its relevance to increasing the value in supporting each decision.

\section{Retrofit decision-making environment}

This section describes a retrofit decision-making environment (illustrated in Fig. 1) that enables two distinct levels of analysis: (a) aggregate-level analysis of multiple buildings; and (b) individual-level analysis for single buildings. The aggregate-level analysis is designed to evaluate the effectiveness of business plans or policy on energy reduction in the building portfolio and determine intervention strategies necessary to reach certain overall energy improvement targets. This capability is useful to stakeholders including analysts in designing or assessing policy, utilities in designing energy efficiency programs, and large organizations in managing building portfolios. The individual-level analysis, on the other hand, is designed to evaluate effectiveness and underperformance risks associated with alternative 
EEM implementations for a specific building. This capability can inform building owner decisions as well as energy service contract terms.

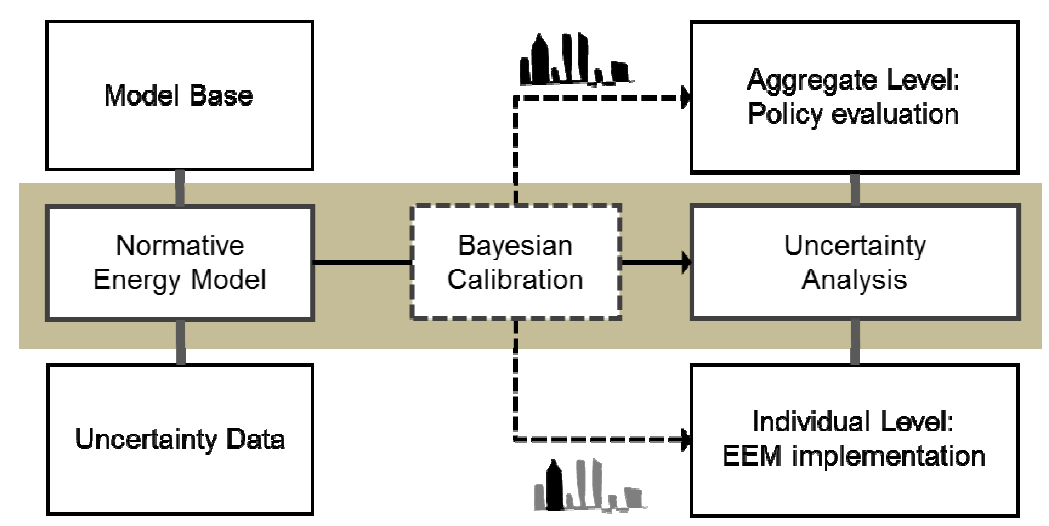

Fig. 1. Schematic of the overall retrofit decision-making environment

\subsection{Methodology}

The energy model used in the decision-making environment is a normative energy model derived from the European Committee for Standardization and the International Organization for Standardization $[22,23]$ and translated by the Georgia Institute of Technology into an Energy Performance Standard Calculation Toolkit [24]. The normative model is a light-weight quasi-steady-state model that calculates monthly energy consumption by main end-uses by approximately capturing major characteristics of a building and systems. This representation, with a much smaller set of parameters, increases modelling efficiencies for aggregate-level analysis by greatly alleviating burdens in data collection, model construction, and computation. In addition, the normative model defines a set of consistent rules for specifying envelope properties, systems efficiency, and building usage and operation scenarios for calculating and rating the energy performance of new and existing buildings. Its simplicity and unified modelling assumptions allow this approach to assess the energy performance of large numbers of buildings in a standardized and transparent way [25].

The calibration approach used in the environment is a Bayesian approach that quantifies uncertainty in calibration parameters while updating parameter values given measured energy-use data. Calibration of building energy models has been applied to reliably predict energy-saving potentials for EEMs in the retrofit analysis process $[26,27,28]$. The Bayesian approach is well suited for uncertainty analysis because it explicitly quantifies uncertainties in the energy model during the calibration process. Under the Bayesian paradigm, prior beliefs about true values for calibration parameters are quantified in a form of probability density functions. The prior distributions are updated through the likelihood function that compares how closely model outputs match measured energy-use data. As a result, the Bayesian calibration provides a set of refined input parameter values, referred to as posterior distributions. A recent paper [29] summarizes the mathematical formulation and computation of Bayesian calibration and demonstrates the efficacy of Bayesian calibration under different levels of uncertainty. 
The analysis approach underlying the decision support is an uncertainty analysis framework that accounts for major sources of uncertainty to predict a range of possible energy savings and their likelihoods. The uncertainty analysis framework propagates uncertainty in the baseline energy model, input parameters, and energy performance of EEMs to compute energy savings in a probabilistic form. Since the energy model cannot analytically derive the probabilistic distribution of energy savings, we apply a Latin Hypercube Sampling (LHS) method [30]Error! Reference source not found. that draws samples from the probability distributions of uncertain parameters. The LHS method has been regarded as an efficient sampling method that captures the theoretical probability density function with reduced number of samples. The resulting probabilistic predictions can be translated into single values that reflect decisionmaker's objectives and risk attitude, which will be described in Section 2.4.

\subsection{Model base}

Given its reduced set of data requirements, the normative model facilitates the development of a model base for large building sets. Unlike the current retrofit practice that relies heavily on experienced energy auditors to collect detailed data for transient simulation models, the normative nature and simplicity of our approach makes it feasible to collect necessary data from the community (e.g., building owners or facility managers) and construct urban-scale energy models without intensive processes.

To streamline data requirements in the audit form (i.e., questionnaire), we characterize model parameters according to types of data sources and the difficulty of finding them. Model parameters are categorized into six types: (1) building geometry, (2) envelope thermal properties, (3) mechanical system, (4) control settings, (5) building use, and (6) ventilation. Building geometry can be fairly approximated from GIS databases or Google images. Envelope thermal properties can be calculated using standard thermal property values for different construction material types [31] based on the construction materials identified in the audit form. The audit form requests information about HVAC system type for heating, cooling, ventilation, and distribution, system efficiencies, and control settings (i.e., indoor setpoint temperatures, operation schedules) that is easily obtained from facility managers who supervise building operation. On the other hand, attaining accurate values for building use and ventilation is quite difficult. Estimating values for internal demands involves a laborious task of counting the number of occupants, appliances, and lighting fixtures, whereas estimating infiltration and outdoor airflow rates requires flow meter installation and measurement under standard conditions. For such parameters, we derived parameter values on the basis of existing field surveys of commercial buildings to supplement the data collected through community efforts.

\subsection{Uncertainty data}

Uncertainty associated with model parameters is quantified according to the audit level of data collection. The data level determines sources of uncertainty that determine the range of possible values for model parameters and ultimately impacts the confidence interval of model predictions [29]. The process of quantifying uncertainty involves identifying uncertain parameters that potentially impact the model outcome and quantifying their uncertainty in a form of a probability density function. For identified uncertain parameters, we assign a triangular distribution with the minimum, mode, and maximum values derived from the existing body of evidential knowledge (e.g., technical reports, industry reports, industry standards). 
Uncertainty in envelope thermal properties is quantified on the basis of standard deviations of uncertainties specified in Macdonald [32]. He quantified the standard deviation of uncertainties in Uvalue, density, and specific heat to be $5 \%, 1 \%$, and $12.25 \%$, respectively, and also summarized the standard deviation of uncertainties in solar absorptance and emissivity for different materials. For mechanical systems whose rated efficiency values are obtained, actual system efficiency may still differ from the rated efficiency measured under standard conditions. Uncertainty in actual system efficiency is quantified with use of maximum allowable tolerances stipulated in the industry standards for different system types. The maximum tolerance is $2 \%$ for boilers and burners [33], $5 \%$ for air-conditioners and heat pumps [34,35][33], and the function of difference between entering and leaving chilled water temperatures for water-based chillers [36]. The efficiency of mechanical ventilation systems depends on systems efficiency, system configuration, and control settings. The overall efficiency of mechanical ventilation systems is defined as specific fan power $\left(\mathrm{W} / \mathrm{s} . \mathrm{m}^{2}\right)$. Instead of attaining detailed information about secondary equipment, the possible range of specific fan power values is quantified depending on the system configuration type on the basis of the industry report [37]. For a wide range of temperature differences $\left(5-40^{\circ} \mathrm{C}\right)$, the maximum tolerance for chillers remains within $5 \%$. In addition, uncertainty in indoor temperatures is quantified to vary within $\pm 1.5^{\circ} \mathrm{C}$ around the set-point temperatures obtained from the audit form [38].

Building-use parameters (i.e. internal loads, domestic hot water (DHW) demand) are significantly impacted by building function. Since our pilot study targets office buildings, we quantify uncertainty in these parameters to capture variation observed in existing surveys of office buildings. ASHRAE handbook [38] estimates that daily DHW demands for office buildings fall between 3.8 and 7.6 1/day per occupant. Dunn and Knight [39] summarizes that occupant densities range between $4.3-22.80 \mathrm{~m}^{2} /$ person and appliance power densities between $6-34 \mathrm{~W} / \mathrm{m}^{2}$ on the basis of the survey of 30 office buildings. The CIBSE Guide A [40] estimates from office building surveys that maintained illumination levels are in the range of $350-500$ lux. The uncertainty range of lighting power densities is calculated from the uncertainty range of the lighting level and standard power density values per 100 lux for different lamp types specified in the SBEM technical manual [41].

Uncertainty in infiltration is quantified on the basis of an extensive dataset of existing fan pressurized tests summarized in [42]. After excluding low-rise building cases from the dataset, uncertainty in infiltration for high-rise commercial buildings is estimated to range between $0.5-4.0 \mathrm{~m} / \mathrm{s}$ per exterior envelope area at $4 \mathrm{~Pa}$. Similarly, uncertainty in outdoor airflow rate is quantified on the basis of the existing dataset of measured mechanical ventilation rates from 100 office buildings [43]. The fraction of actual-to-design outdoor airflow rate ranges between 0.3 and 2.3 (1.0 indicating the actual airflow rate is the same as the design one) for outdoor air systems without economizer cycle. On the basis of the same dataset, supply airflow rate is estimated to fall between 2.7 and $11.2 \mathrm{~L} / \mathrm{s} . \mathrm{m}^{2}$ with a mean of $7.0 \mathrm{~L} / \mathrm{s} . \mathrm{m}^{2}$ for constant air volume systems and to fall between 1.7 and $7.8 \mathrm{~L} / \mathrm{s} . \mathrm{m}^{2}$ with a mean of $5.5 \mathrm{~L} / \mathrm{s} . \mathrm{m}^{2}$ for variable air volume systems.

\subsection{Decision analysis contexts}

In decision analysis, performance indicators and risk measures need to be designed to reflect a decision-

maker's objective and risk attitude. Table 1 lists performance indicators and associated risk measures for typical decision-making contexts at the aggregate and individual-level. The aggregate-level analysis 
targets inspection and forward projection of different energy improvement scenarios over time for any collection of buildings. We use the percent of energy-savings-to-baseline $\left(f_{\text {saving }}\right)$ as the performance indicator and the expected value of the indicator values as the risk measure. The expected value of the indicator, denoted as $E\left(f_{\text {saving }}\right)$, is a weighted average of all possible indicator values that accounts for the magnitude of energy reductions and their likelihoods. In this way, the expected value differs from the deterministic value that represents a single, most likely case. At the individual level, one needs to closely inspect the energy savings potentials of EEMs and associated underperformance risks to ensure whether selected EEMs meet certain energy savings required for regulated energy efficiency programs or performance-based contracts. The risk measure for the individual level is represented by the 5-quantile of annual energy-saving predictions, $q_{05}\left(E_{\text {saving }}\right)$.

\section{Table 1}

Typical decision-making contexts and associated decision measures

\begin{tabular}{lll}
\hline Decision-making context & Performance indicator & Risk measure \\
\hline (a) Policy evaluation & Percent of energy-savings to baseline $(\%)$ & $E\left(f_{\text {saving }}\right)$ \\
(b) EEM decision & Annual energy-saving $\left(\mathrm{kWh} / \mathrm{m}^{2}\right)$ & $q_{05}\left(E_{\text {saving }}\right)$ \\
\hline
\end{tabular}

\section{Calibration of normative models}

This section illustrates the calibration process through a case study of office buildings located in the business district of Chicago known as the "Chicago Loop." We selected two high-rise office buildings: Case A is a 71-story building with a high window-to-wall ratio (approximately 1:1), and Case B is a 26story building with a smaller window-to-wall ratio (1:4). The two buildings are made of pre-cast concrete with insulation for walls and double-glazing for windows. They are equipped with electric heaters in airhandling units for heating and centrifugal chillers for cooling. They have T-8 fluorescent lamps for artificial lighting and electric water heaters for domestic hot water supply. We modelled the case buildings on the basis of the data collected from the audit form and calibrated them with the wholebuilding monthly utility bills.

The calibration process consists of four steps: (1) prior uncertainty quantification, (2) parameter screening, (3) model calibration, and (4) model validation. Uncertain parameters in the models are assigned with prior distributions quantified as described in Section 2.3 given the building features. Then, a parameter screening method, specifically the Morris method, is applied to select a smaller set of dominant parameters that have the most significant effect on energy predictions. The Morris method computes a main effect per parameter that explains the average change in the model output as the result of changes in the parameter [44]. The main effects computed by the Morris method provide a relative measure of the effect of uncertain parameters on model outcomes, with higher main effect values indicating higher parameter significance rankings. Table 2 summarizes the ranking of uncertain parameters for Cases A and $B$ in terms of their effect on energy-use intensity $\left(\mathrm{kWh} / \mathrm{m}^{2}\right)$. Overall, the two cases resulted in the same ranking of the top dominant parameters; the most dominant parameters are infiltration rate followed by appliance power density, lighting power density, and deviation from heating setpoint temperature. Hence, we selected the same four parameters to calibrate the models for the two cases. 
Table 2

Ranking of uncertain parameters for Cases A and B (unit: $\mathrm{kWh} / \mathrm{m}^{2}$ )

\begin{tabular}{clrlr}
\hline Rank & \multicolumn{1}{c}{ Case A } & Main & Model parameter & Main \\
& Model parameter & 146.0 & Infiltration rate & 115.3 \\
1 & Infiltration rate & 96.4 & Appliance power density & 95.6 \\
2 & Appliance power density & 38.8 & Lighting power density & 36.4 \\
3 & Lighting power density & 33.6 & Deviation from heating setpoint & 22.6 \\
4 & Deviation from heating setpoint & & temperature & \\
& temperature & 14.0 & Fraction of actual to design airflow & 12.2 \\
5 & Fraction of actual to design airflow & 11.1 & Occupant density & 11.4 \\
6 & Occupant density & 8.4 & DHW demand & 6.3 \\
7 & Indoor temperature during cooling & 6.4 & Indoor temperature during cooling & 5.7 \\
8 & DHW demand & 5.9 & Specific fan power & 4.7 \\
9 & Specific fan power & 5.1 & Heat capacity & 3.4 \\
10 & Heat capacity & & & \\
\hline
\end{tabular}

Then, the Bayesian calibration module calibrates the selected parameters given their prior distributions, one-year monthly utility bills, and the normative energy model of the respective buildings. We use actual weather conditions in 2009, measured in the Chicago O'Hare international airport, that correspond to the utility bills. Fig. 2 displays posterior distributions of the calibration parameters for Case A (dotted-line histogram) and Case B (grey-filled histogram) in comparison to prior distributions (black solid line). Fig. 2 clearly shows that Bayesian calibration can significantly reduce uncertainty in some model parameters. For infiltration rate, the range of plausible values was greatly reduced for the two cases, and the expected value for Case A is $2.0 \mathrm{~m}^{3} / \mathrm{s} \cdot \mathrm{m}^{2}$, slightly lower than that for Case B $\left(2.3 \mathrm{~m} / \mathrm{s} \cdot \mathrm{m}^{2}\right)$. For appliance and lighting power densities, actual values for Case B are likely to be higher than the prior estimates, whereas actual values for Case A are likely to be typical values specified in the prior distributions. For the deviation from heating setpoint temperature, actual temperatures for the two cases are likely to be $0.5^{\circ} \mathrm{C}$ higher than the set-point temperature. The two cases resulted in quite different posterior distributions for appliance and lighting power densities although they are high-rise office buildings in the same business district. Since the cases are located in the same climate and made of the same construction materials, discrepancy between the posterior distributions is much smaller for infiltration rate. We highlight that Bayesian calibration provides the generic mathematical framework for calibrating any building and resulting posterior distributions may reflect differences between buildings. In our study, Bayesian calibration substantially reduced uncertainty for infiltration rate in Case A, but, in Case B, it significantly reduced uncertainty for most of the calibration parameters. We will use these two example cases to further inspect the effect of calibration on retrofit decisions. 

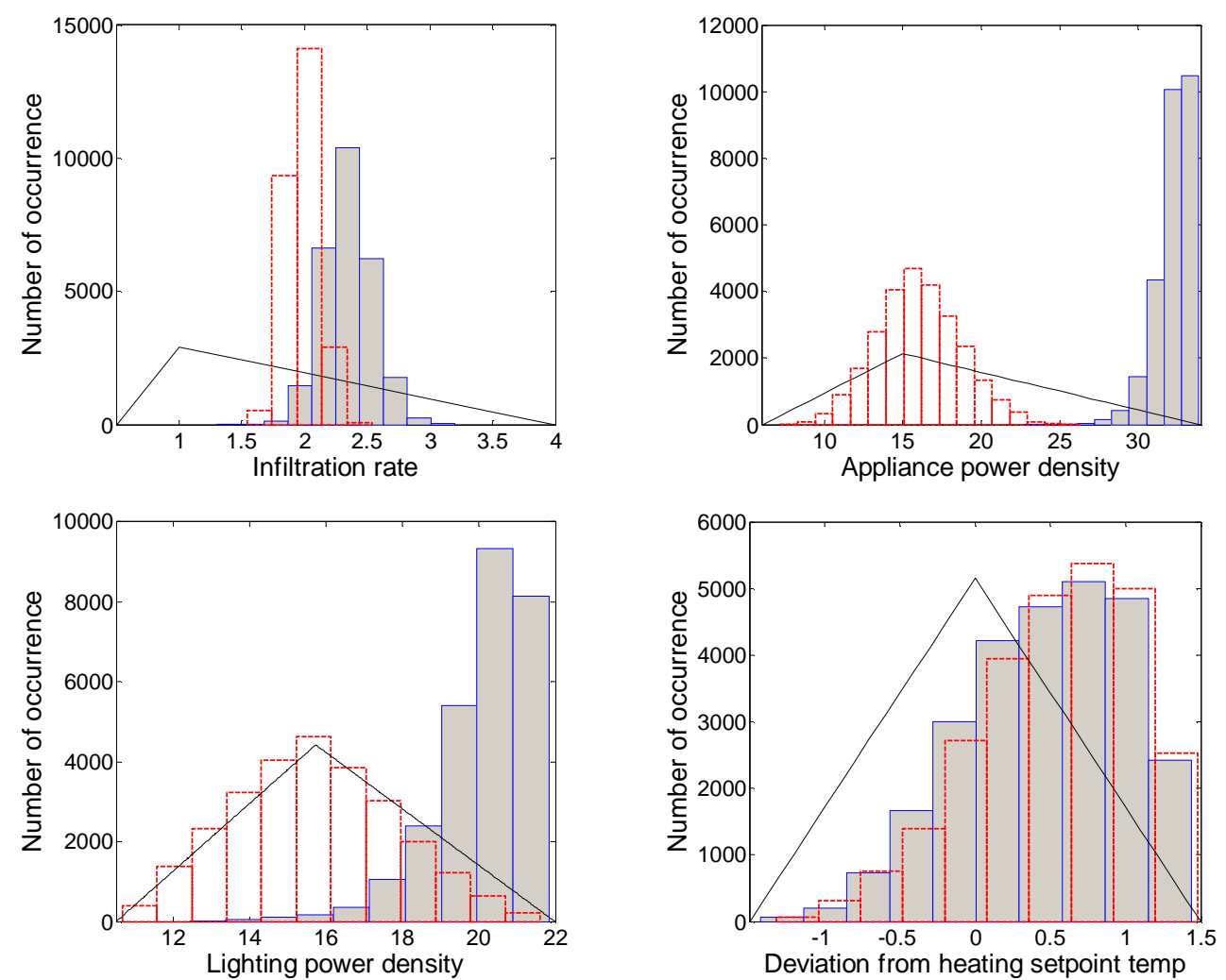

Fig. 2. Posterior distributions of calibration parameters (dotted-line histogram for Case A and grey-filled histogram for Case B) in comparison to prior distributions (black solid line)

Last, calibrated models are validated with use of a standard validation measure, the coefficient of variation of the root mean square error (CVRMSE) specified in the ASHRAE guideline [28]. The guideline stipulates that CVRMSE between monthly predicted and actual energy consumptions should be within $15 \%$ in order for the calibrated model to be deemed valid. Table 3 shows CVRMSE values of uncalibrated and calibrated models for the two cases. We applied the LHS method to draw samples from the uncertainty distributions of the calibration and other parameters, computed the distribution of monthly energy predictions associated with samples, and compared each value in the distribution with one measurement value for each month. For both cases, calibration significantly enhanced the accuracy of monthly energy predictions by reducing CVRMSE values by half. For Case B, which has higher discrepancy between predicted and actual energy use, calibration updated uncertain parameter values to a significant degree and produced predictions with similar degree of confidence as the calibrated model for Case A.

Table 3

CVRMSE values of uncalibrated and calibrated models for Cases A and B

\begin{tabular}{lcc}
\hline & Case A & Case B \\
& CVRMSE & CVRMSE \\
\hline Uncalibrated model & 0.28 & 0.38 \\
Calibrated model & 0.15 & 0.16 \\
\hline
\end{tabular}




\section{Uncertainty analysis for energy-saving predictions}

This section examines the disparity of predictions between the uncalibrated and calibrated models by deploying them in decision-making contexts for predicting energy-saving potentials of feasible retrofit options. We consider four EEMs: (1) air-tightening the envelope, (2) upgrading lighting systems to T-5 fluorescents, (3) installing an energy recovery system, and (4) installing occupancy sensors. Table 4 summarizes model parameters associated with the four EEMs and their uncertainty ranges on the basis of the literature: [45], [46], [47], [48] for EEMs 1 to 4, respectively. The effect of air-tightening the envelope is captured by a model parameter, infiltration rate reduction (\%), and the range of the reduction is derived from existing pressurization data measured before and after implementation of an air-tightening measure [45]. The lighting occupancy factor is a normative correction factor that explains the effect of occupancy sensors on reducing lighting energy use with accounting for control settings and spatial layout [48]. We highlight that the relative magnitude of uncertainty associated with EEMs varies depending on the EEM type. For instance, EEMs 2 and 3 have a small relative magnitude of uncertainty arising from the deviation between actual and rated system efficiencies, whereas EEM 1 has a higher relative magnitude of uncertainty due to various factors (e.g., craftsmanship, weather and building operation conditions) that impact air infiltration.

\section{Table 4}

Quantification of uncertainty in model parameters associated with four EEMs

\begin{tabular}{lccc}
\hline EEMs & Base & Min & Max \\
\hline $\begin{array}{c}\text { EEM 1: Air-tightening the envelope } \\
\text { Infiltration rate reduction (\%) }\end{array}$ & 11.00 & 1.00 & 31.00 \\
$\begin{array}{c}\text { EEM 2: Upgrading lighting system } \\
\text { Lighting power density }\left(\mathrm{W} / \mathrm{m}^{2}\right)\end{array}$ & 9.40 & 9.10 & 9.70 \\
$\begin{array}{l}\text { EEM 3: Installing energy recovery system } \\
\quad \begin{array}{l}\text { System efficiency } \\
\text { EEM 4: Installing occupancy sensor } \\
\text { Lighting occupancy factor }\end{array}\end{array}$ & 0.70 & 0.67 & 0.74 \\
& 0.70 & 0.60 & 0.80 \\
\hline
\end{tabular}

Using the LHS method, we propagate uncertainties associated with the uncalibrated and calibrated models and EEM parameters to compute probability distributions of energy-savings predictions. Results are shown in Fig. 3. We use a two-sample Kolmogorov-Smirnov test (K-S test) to quantitatively evaluate whether probabilistic outcomes projected by the uncalibrated and calibrated models are identical for each of the case studies. The two-sample K-S test checks the location and the shape of the two samples to confirm whether the two samples come from the same cumulative distribution [49]. The test hypothesizes that the two samples are from the same distribution, denoted as $H=0$, and rejects the hypothesis $(H=1)$ when they are different at the 5\% significance level. The K-S test compares the empirical cumulative distribution functions of the two samples by quantifying a vertical distance between the two samples at each percentile and computes a $D$ statistic that indicates the maximum distance between the two distributions. The $p$-values reported in Table 5 show that the K-S test rejects the hypothesis at the 5\% significance level for all EEM predictions. This result indicates that the uncalibrated model does not yield 
probabilistic outcomes equivalent to those by the calibrated model. The $D$ statistic value is highest for predicting EEM 2 in Case B, which suggests that calibration greatly impacted energy-saving predictions particularly for EEM 2. This large discrepancy is attributed to significant uncertainty reduction in the baseline lighting power density (shown in Fig. 2) as the result of Bayesian calibration. For the other EEMs, the uncalibrated model computed energy-saving predictions aligned with those predicted by the calibrated model, although discrepancy in predictions exists between the two models as shown in Fig. 3. This predicted discrepancy will be further inspected with respect to its effect on decision-making.

Table 5

K-S test results for comparing predictions from the uncalibrated and calibrated models

\begin{tabular}{ccccccc}
\hline & & Case A & & & Case B & \\
\cline { 2 - 7 } & $H$ & $p$-value & $D$ Statistics & $H$ & $p$-value & $D$ Statistics \\
\hline$f_{\text {saving }}$ & & & & & & \\
EEM 1 & 1 & 0.00 & 0.26 & 1 & 0.00 & 0.13 \\
EEM 2 & 1 & 0.00 & 0.17 & 1 & 0.00 & 0.49 \\
EEM 3 & 1 & 0.00 & 0.22 & 1 & 0.00 & 0.33 \\
EEM 4 & 1 & 0.00 & 0.23 & 1 & 0.00 & 0.18 \\
\hline$E_{\text {saving }}$ & & & & & & \\
EEM 1 & 1 & 0.00 & 0.27 & 1 & 0.00 & 0.26 \\
EEM 2 & 1 & 0.00 & 0.17 & 1 & 0.00 & 0.76 \\
EEM 3 & 1 & 0.00 & 0.23 & 1 & 0.00 & 0.08 \\
EEM 4 & 1 & 0.00 & 0.19 & 1 & 0.00 & 0.54 \\
\hline
\end{tabular}


Case A
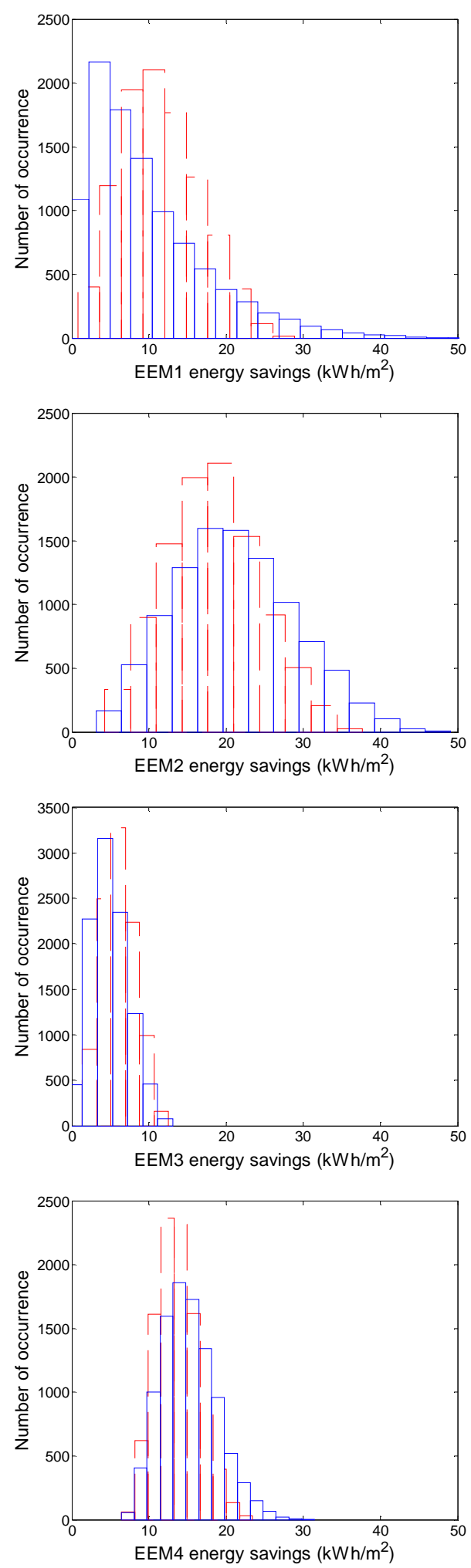

Case B
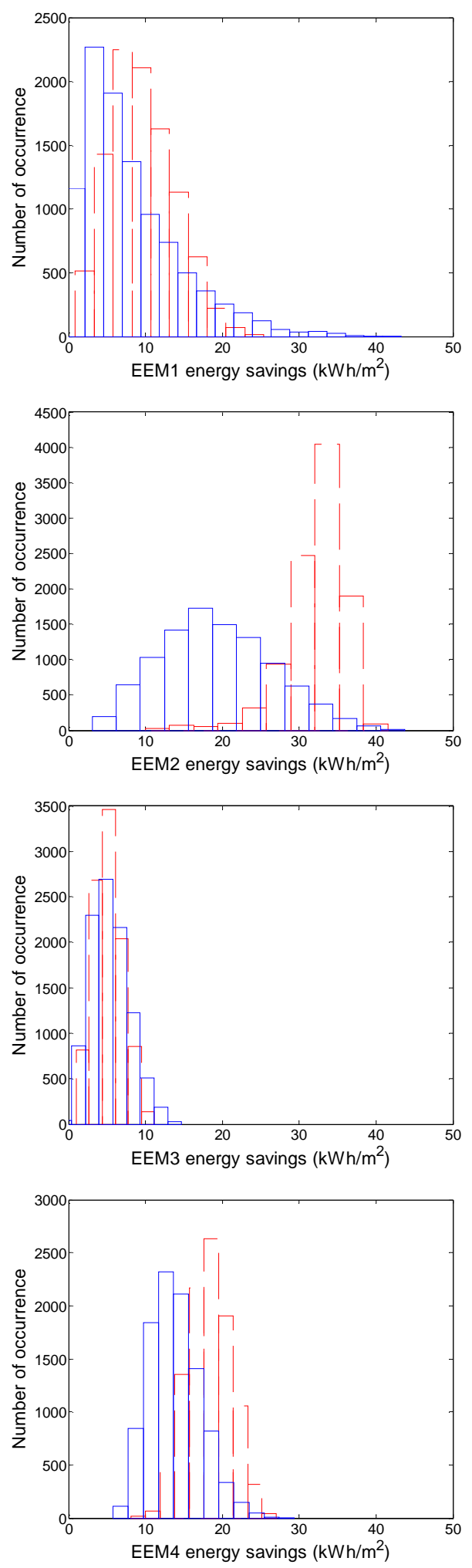

Fig. 3. Predictions of annual energy-savings for Case A (left side) and Case B (right side): calibrated model - red dotted line; uncalibrated model - blue solid line 


\section{Relevance of calibration in retrofit decision-making}

This section investigates whether calibration plays a significant role in supporting energy retrofit decisions. We compare predicted decision measures and final decisions derived by the uncalibrated model with those derived by the calibrated model in the two retrofit decision-making contexts summarized in Section 2.4. Table 6 summarizes the decision measure values and ranking of EEMs predicted by the two models in the policy evaluation context. Overall, the two models yielded similar predictions and the same ranking of the EEMs for evaluating the effectiveness of EEMs over the building portfolio. When the results are viewed for individual buildings, the calibrated models computed slightly different estimates for EEMs 1 and 2 in which EEM baseline conditions were substantially updated from the same prior distribution, as compared to the uncalibrated models that computed nearly the same energy-saving estimates associated with each EEM for the two cases. Furthermore, aggregating the effect of EEMs for two buildings reduced the difference of predictions between the uncalibrated and calibrated models in comparison to the individual-building comparison. Further study with more case studies is needed to confirm whether the normative model without calibration could be adequate to comparatively evaluate different retrofit scenarios over a large number of buildings.

\section{Table 6}

Comparison of EEMs to support policy evaluation (Unit: percent of annual energy savings to baseline)

\begin{tabular}{ccccc}
\hline & Calibrated & Model & \multicolumn{2}{c}{ Uncalibrated } \\
$E\left(f_{\text {saving }}\right)$ & Rank & $E\left(f_{\text {saving }}\right)$ & Rodel \\
\hline All Cases & & & & 3 \\
EEM 1 & 4.2 & 3 & 4.0 & 1 \\
EEM 2 & 10.0 & 1 & 9.4 & 4 \\
EEM 3 & 2.2 & 4 & 6.4 & 2 \\
EEM 4 & 6.3 & 2 & 6.8 & 3 \\
\hline Case A & & & 4.0 & 1 \\
EEM 1 & 5.1 & 3 & 9.4 & 4 \\
EEM 2 & 8.0 & 1 & 2.2 & 2 \\
EEM 3 & 2.7 & 4 & 6.8 & 3 \\
EEM 4 & 6.0 & 2 & & 1 \\
Case B & & & 3.8 & 4 \\
EEM 1 & 3.5 & 3 & 9.5 & 2 \\
EEM 2 & 11.7 & 1 & 2.6 & \\
EEM 3 & 1.9 & 4 & 6.9 & \\
EEM 4 & 6.6 & 2 & & \\
\hline
\end{tabular}

We also evaluate the two models to test whether they derive consistent results in supporting riskconscious decision-making for individual buildings. Table 7 summarizes 5-quantiles of annual energysavings predicted by the two models in the context of performance-based contracts. Overall, the calibrated and uncalibrated models resulted in different ranking of EEMs. For Case A, the two models yielded the same ranking for the two top EEMs but different ranking for the other EEMs. For Case B in which calibration significantly reduced the uncertainty range of the calibration parameters, the calibrated model substantially reduced the uncertainty range of probabilistic outcomes, especially for EEM 2, in comparison to the uncalibrated model. This comparison suggests that the energy models without 
calibration have potential for biasing retrofit decisions on the choice of EEMs. Moreover, the models without calibration yielded more conservative estimates for the guaranteed energy-saving estimated than the calibrated models. Hence, model calibration shows promise of reducing uncertainty in predictions, thereby reducing performance risks factored into ESCO's service costs.

\section{Table 7}

Comparison of EEMs to support performance-based contract (Unit: $\mathrm{kWh} / \mathrm{m}^{2}$ )

\begin{tabular}{ccccc}
\hline & Calibrated & Model & \multicolumn{2}{c}{ Uncalibrated } \\
& $q_{05}\left(E_{\text {saving }}\right)$ & Rank & $q_{05}\left(E_{\text {saving }}\right)$ & Model \\
\hline Case A & & & & \\
EEM 1 & 3.9 & 3 & 1.4 & 4 \\
EEM 2 & 8.5 & 2 & 1.8 & 3 \\
EEM 3 & 2.8 & 4 & 9.9 & 1 \\
EEM 4 & 9.6 & 1 & & 4 \\
Case B & & & 1.3 & 2 \\
EEM 1 & 3.3 & 3 & 8.1 & 3 \\
EEM 2 & 25.3 & 1 & 1.7 & 1 \\
EEM 3 & 2.3 & 4 & 9.0 & \\
EEM 4 & 13.7 & 2 & & \\
\hline
\end{tabular}

\section{Conclusions}

This paper presents a scalable analytic methodology that supports retrofit decision-making at the individual and aggregate levels. The methodology allows decision makers to evaluate policy and planning options in the context of the actual building portfolio and informs individual building stakeholders of specific retrofit strategies suited to their buildings by assessing performance risk associated with retrofit technologies. In supporting these various decision-making contexts, it examines the relevance of model calibration to support retrofit decision making by using a case study of office buildings. The case study demonstrates that calibration reduces the uncertainty of model predictions. Despite discrepancies between the uncalibrated and calibrated model outcomes, the case study suggests that the uncalibrated model can properly perform comparative analysis to rank retrofit scenarios at the aggregate level. On the other hand, for individual building assessments, results support the value of model calibration for risk-conscious decision-making by reducing the uncertainty in model predictions.

The proposed methodology provides the generic analysis framework that can incorporate all sources of uncertainty for EEM predictions. Nonetheless, the sources of uncertainty in the case study are limited to physical properties, system efficiencies, and operation settings. In regard to technical performance, the case study ignores uncertainty arising from system degradation over time. In order to more fully evaluate the investment risks for EEMs, the methodology needs to incorporate the full spectrum of uncertainties associated with not only technical performance but also financial factors (e.g., capital cost, energy cost projection, financial incentives), behavioural factors (e.g., changes in occupant behaviour) and multiple stakeholders involved in the decision process. In the process of uncertainty quantification, uncertainties in model parameters are regarded as static (constant over time). For time-varying parameters in which the magnitude of uncertainty may differ over time horizon, further studies are needed to capture time-series variation in uncertainty. 
The proposed modelling methodology can be applicable for modelling any building type and evaluating any EEMs when (1) the audit form can collect all relevant information to capture building and systems characteristics for different building types and (2) the normative model can capture the effect of EEMs. The audit form used in the case study is limited to commercial buildings in which the dominant space type is office and central mechanical systems provide heating and cooling for the entire building. In order to model any commercial buildings, the audit form needs to be expanded to capture different types of tenants and associated independent mechanical systems within a building. The normative model can represent EEMs associated with the building envelope, mechanical systems, and lighting systems. The normative model represents system behaviour with a set of aggregated-level parameters based on monthly average weather operation conditions; it computes overall system efficiency based on normative factors that account for primary system efficiency, their configuration and control settings. As a result, it is not currently able to adequately evaluate some system-related EEMs when they are tightly related to the dynamics of building operation (e.g., economizers) or they are upgrading secondary equipment (e.g., upgrading high-efficient pumps or high-efficient fans). In order to improve the capability of the normative model, work is on-going to expand a set of normative factors that account for secondary systems and dynamic building operation in relation to outdoor weather conditions.

\section{Acknowledgment}

This work was supported by the US Department of Energy under Contract No. DE-AC02-06CH11357.

\section{References}

[1] U.S. DOE, Buildings energy data book, available from http://www.btscoredatabook.net/ChapterIntro1 .aspx, 2012.

[2] GOV.UK, Improving the energy efficiency of buildings and using planning to protect the environment, available from https://www.gov.uk/government/policies/improving-the-energyefficiency-of-buildings-and-using-planning-to-protect-the-environment/supporting-pages/energyperformance-of-buildings, 2014

[3] EIA, Commercial building energy consumption survey (CBECS), available from http://www.eia.gov/consumption/commercial, 2014.

[4] IPCC, Summary for policymakers, in: B. Metz, O.R. Davidson, P.R. Bosch, R. Dave, L.A. Meyer (Eds.), Climate Change 2007: Mitigation. Contribution to Working Group III to the Fourth Assessment Report of the Intergovernmental Panel on Climate Change, Cambridge University Press, 2007.

[5] CTC766, Building the future today: transforming the economic and carbon performance of the buildings we work in (CTC765), Technical Report, The Carbon Trust, 2009.

[6] Xenergy, California statewide commercial energy efficiency potential study, volume 1, Report prepared for Pacific Gas and Electric Company, Burlington, MA, 2002.

[7] NPPC, The fifth Northwest power and conservation plan, Report, Northwest Power Planning Council, available from http://www.nwcouncil.org/energy/powerplan/5/plan/, 2005.

[8] U.S. DOE, Better buildings challenge, available from http://www4.eere.energy.gov/challenge/home, 2014 
[9] City of Chicago, Chicago climate action plan, available from http://www.chicagoclimateaction.org, 2014.

[10] A. Uihlein, P. Eder, Policy options towards an energy efficient residential building stock in the EU27, Energy and Buildings, 2010;42:791-798.

[11] Y. Shimoda, T. Fukii, T. Moprikawa, M. Mizuno, Residential end-use energy simulation at city scale, Building and Environment, 2004;39:959-967.

[12] A.T. Booth, R. Choudhary, D.J. Spiegelhalter, Handling uncertainty in housing stock models, Building and Environment, 2012;48:35-47.

[13] B. Coffey, S. Borgeson, S. Selkowitz, J. Apte, P. Mathew, P. Haves, Towards a very low-energy building stock: modelling the US commercial building sector to support policy and innovation planning, Building Research \& Information, 2009;37(5-6):610-624.

[14] Y.Yamaguchi, Y. Shimoda, M. Mizuno, Proposal of a modelling approach considering urban form for evaluation of city level energy management, Energy and Buildings, 2007;39:580-592.

[15] S.J. Hansen, J.W. Brown, Investment Grade Energy Audit: making smart energy choices, Fairmont Press, Lilburn, GA, 2004.

[16] IPMVP, International performance measurement and verification protocol: concepts and options for determining energy and water savings, vol.1, Technical Report, Efficiency Valuation Organization, 2010.

[17] Y. Pan, Z. Huang, G. Wu, Calibrated building energy simulation and its application in a high-rise commercial building in Shanghai, Energy and Buildings, 2007;39:651-657.

[18] Y. Zhu, Applying computer-based simulation to energy auditing: a case study, Energy and Buildings, 2006;38:421-428.

[19] A. Pedrini, F.S. Westphal, R. Lamberts, A methodology for building energy modelling and calibration in warm climates, Building and Environment, 2002;37:903-912.

[20] Y. Heo, R. Choudhary, G.A. Augenbroe, Calibration of building energy models for retrofit analysis under uncertainty, Energy and Buildings, 2012;47:550-560.

[21] Y. Heo, G.A. Augenbroe ,R. Choudhary, Quantitative risk management for energy retrofit projects, Journal of Building Performance Simulation, 2013;6(4):1-12.

[22] ISO 13790:2008, Energy performance of buildings - calculation of energy use for space heating and cooling, International Organization for Standardization, 2008.

[23] EN 15243:2007, Ventilation for buildings - calculation of room temperatures and of load and energy for buildings with room conditioning systems, European Committee for Standardization, 2007.

[24] S.H. Lee, F. Zhao, G. Augenbroe, The use of normative energy calculation beyond building performance rating systems, Journal of Building Performance Simulation, 2013;6(4):282-292.

[25] J. Hogeling, D. Dijk, P60: more information on the set of CEN standards for the EPBD, European Commission, 2008.

[26] T.A. Reddy, Literature review on calibration of building energy simulation programs: uses, problems, procedures, uncertainty, and tools, ASHRAE Transactions, 2006;226-240.

[27] G. Liu, M. Liu, A rapid calibration procedure and case study for simplified simulation models of commonly used HVAC systems, Building and Environment, 2011;46(2):409-420.

[28] ASHRAE, ASHRAE Guideline 14: Measurement of Energy and Demand Savings, American Society of Heating, Refrigerating, and Air Conditioning Engineers, 2002. 
[29] Y. Heo, D.J. Graziano, L. Guzowski, R.T. Muehleisen, Evaluation of calibration efficacy under different levels of uncertainty, Journal of Building Performance Simulation, 2014: DOI:10.1080/19401493.2014.8969.

[30] A. Saltelli, M. Ratto, T. Andres, F. Campolongo, J. Cariboni, D. Gatelli, M. Saisana, S. Tarantola, Global Sensitivity Analysis, The Primer, John Wiley \& Sons, West Sussex, England, 2008.

[31] ASHRAE Handbook, Fundamentals, American Society of Heating, Refrigerating and Air Conditioning Engineers, 2009.

[32] I.A. Macdonald, Quantifying the effects of uncertainty in building simulation, PhD Thesis, University of Strathclyde, available from http://www.esru.strath.ac.uk/Documents/PhD/macdonald thesis.pdf, 2002.

[33] R. Kemna, M. van Elburg, W. Li, R. van Holsteijn, Preparatory study on eco-design of CH-boilers: task 1 - definition, test standards, current legislation \& measures, Final Report, European Commission, 2007.

[34] ANSI/AHRI Standard 210/240, Performance Rating of Unitary Air-Conditioning \& Air-Source Heat Pump Equipment, Air-Conditioning, Heating, and Refrigeration Institute, Arlington, VA, 2008.

[35] ANSI/AHRI Standard 310/380, Standard for Packaged Terminal Air-Conditioners and Heat Pumps, Air-Conditioning, Heating, and Refrigeration Institute, Arlington, VA, 2004.

[36] ANSI/AHRI Standard 550/590, Performance Rating of Water-Chilling Packages Using the Vapor Compression Cycle, Air-Conditioning, Heating, and Refrigeration Institute, Arlington, VA, 2003.

[37] P. Radgen, J. Oberschmidt, W.T.W. Cory, EuP Lot 11: fans for ventilation in non residential buildings. Report. Institute Systems and Innovation Research, 2006.

[38] ASHRAE Handbook, HVAC Applications, American Society of Heating, Refrigerating and Air Conditioning Engineers, 2011.

[39] G. Dunn, I. Knight, Small power equipment loads in UK office environments, Energy and Buildings, 2007;37:87-91.

[40] CIBSE Guide A, Environmental Design, The Chartered Institute of Building Services Engineers, 2006.

[41] BRE, A technical manual for SBEM, Report, Building Research Establishment, available from http://www.ncm.bre.co.uk/filelibrary/SBEM_Technical_Manual_v3.5.a_01Mar10.pdf, 2010.

[42] S.J. Emmerich, T. McDowell, W. Anis, Investigation of the impact of commercial building envelope airtightness on HVAC energy use, Report NISTIR 7238, National Institute of Standards and Technology, available from http://fire.nist.gov/bfrlpubs/build05/PDF/b05007.pdf, 2005.

[43] A.K. Persily, J. Gorfain, Analysis of ventilation data from the U.S. environmental protection agency building assessment survey and evaluation (BASE) study, Report NISTIR 7145, National Institute of Standards and Technology, available from http://www.bfrl.nist.gov/IAQanalysis/docs/NISTIR7145Analysis\%20of\%20Ventilation\%20Data\%20from\%20the\%20U.S.\%20Enviro.pdf, 2004.

[44] M.D. Morris, Factorial sampling plans for preliminary computational experiments, Technometrics, 1991;33(2):161-174.

[45] D.I. Jacobson, G.S. Dutt, R.H.Socolow, Pressurization testing, infiltration reduction, and energy savings, in: H.R. Trechsel, P.L. Lagus (Eds.), Measured Air Leakage of Buildings, American Society for Testing and Materials, 1986.

[46] ANSI C78.81, American National Standard for Electric Lamps - Double-Capped Fluorescent Lamps - Dimensional and Electrical Characteristics, National Electrical Manufacturers Association, 2005. 
[47] ANSI/AHRI Standard 1060, Standard for performance rating of air-to-air exchangers for energy recovery ventilation, Air-Conditioning, Heating, and Refrigeration Institute, Arlington, VA, 2005.

[48] PrEN 15193:2006, Energy performance of buildings - energy requirements for lighting, European Committee for Standardization, 2006.

[49] S.M. Ross, Introduction to Probability and Statistics for Engineers and Scientists, Third Edition, Elsevier Academic Press, Burington, MA, 2004. 